\title{
Assessment of the influence of continuous and intermittent irrigation on greenhouse gas emissions from paddy rice
}

\begin{abstract}
The impact of two water management practises on Greenhouse Gases (GHGs) emissions from paddy rice fields was investigated. New Rice for Africa (NERICA 2) lowland variety was planted under intermittent irrigation (II) and continuous flooding (CF) water management practises. Two closed gas chambers (GCs) were developed and used for gas sampling from paddy fields and measurement was done conventionally in all the four growing stages of rice. Gas Chromatograph (GH200-9) was used analysing GHGs such as Methane (CH4), Nitrous oxide (N2O), Hydrogen Sulphide (H2S) and Oxygen (O2). Soil analyses were carried out to determine the presence of the following parameters viz: nitrogen $(\mathrm{N})$, phosphorus $(\mathrm{P})$, potassium $(\mathrm{K})$, magnesium $(\mathrm{Mg})$, Manganese $(\mathrm{Mn})$ and calcium $(\mathrm{Ca})$. Others are Organic Carbon (OC), Moisture Content (MC), Iron (Fe), Chloride (Cl) and Electrical conductivity (EC) using standard laboratory procedures and ascertain effects of their availability on GHGs concentration levels. From the study, no appreciable $\mathrm{CH} 4$ emissions was detected during the four growing stages and under the two water management practises but other GHGs emitted were higher in CF compared with II. Soil nutrients such as $\mathrm{N}, \mathrm{OC}, \mathrm{K}$ and $\mathrm{P}$ also contributed considerably to emissions recorded on the two rice fields. The detection of $\mathrm{H} 2 \mathrm{~S}$ was also an indication that other gases apart from the common GHGs were present in rice fields. Although, $\mathrm{CH} 4$ was not detected, other GHGs emitted were more in CF when compared with II which suggested that II be encouraged as a mitigation strategy for reducing impacts of its emissions.
\end{abstract}

Keyword: Irrigation; Water management; Paddy rice; GHG emissions 